\title{
GÊNERO E CORPO NA CULTURA BRASILEIRA
}

\author{
Mirian Goldenberg*
}

\section{Resumo}

Este trabalho analisa a construção social do corpo a partir dos dados de uma pesquisa realizada com 1279 homens e mulheres das camadas médias brasileiras e da análise de matérias de jornais e revistas nacionais. Pretende-se discutir a construção dos corpos feminino e masculino em uma cultura que transforma corpos "naturais" em corpos aprisionados por modelos inalcançáveis de masculinidade e feminilidade.

Palavras chaves: gênero, corpo, cirurgia plástica, beleza, desvio

\section{Abstract}

\section{GENDER AND BODY IN THE BRAZILIAN CULTURE}

This paper analyzes the social construction of the body in a culture where bodies are imprisoned by unreachable models of masculinity and femininity. The data here presented is taken from a research with 1279 Brazilian middle class men and women and magazines and newspapers articles.

Keywords: gender, body, plastic surgery, beauty, deviance

Nem toda feiticeira é corcunda

Nem toda brasileira é bunda

O meu peito não é de silicone

Sou mais macho do que muito homem

Rita Lee (Pagu)

* Doutora em Antropologia Social; Professora do Programa de Pós-Graduação em Sociologia e Antropologia do Instituto de Filosofia e Ciências Sociais da Universidade Federal do Rio de Janeiro (IFCS-UFRJ). 
Este trabalho analisa a construção social do corpo a partir dos dados de uma pesquisa realizada com 1279 homens e mulheres das camadas médias cariocas e da análise de matérias de jornais e revistas nacionais. Pretende-se discutir a construção do corpo feminino e masculino em uma cultura que transforma corpos "naturais" (Goldenberg, 2002) em corpos aprisionados por modelos inalcançáveis de masculinidade e feminilidade.

Durante muito tempo, temas como corpo e gênero foram considerados menores no campo das ciências sociais brasileiras. Apesar de alguns autores clássicos terem tratado destes temas, já no início do século XX, corpo e gênero demoraram a surgir como objetos privilegiados da antropologia em nosso país. No entanto, no final do século XX e início do XXI, parece ter ocorrido uma verdadeira explosão de trabalhos científicos, em diferentes áreas do conhecimento, que têm como objetivo central discutir a singularidade do corpo e da construção do gênero na nossa cultura.

Antes considerados temas fúteis, sem importância social em um país pobre e com questões muito mais fundamentais - como desemprego, fome ou violência -, corpo e gênero passaram, recentemente, a ser objetos prestigiados no mundo acadêmico, provocando a reflexão de antropólogos, sociólogos, historiadores, psicanalistas, educadores, entre tantos outros profissionais que se preocupam em compreender a cultura brasileira.

Este empenho dos estudiosos em compreender a construção do corpo no Brasil está associado à centralidade que este corpo adquiriu para determinados segmentos sociais. Pode-se afirmar que o final do século XX e o início do século XXI serão lembrados como o momento em que o culto ao corpo se tornou uma verdadeira obsessão, transformando-se em um estilo de vida, pelo menos entre as mulheres das camadas médias urbanas. É fácil perceber que as mulheres de maior sucesso, nos dias de hoje, são as atrizes e as modelos. Antes desconhecidas ou desprestigiadas, as modelos adquiriram status de celebridade na última década e passaram a ter uma carreira invejada (e desejada) pelas adolescentes brasileiras. Ganharam um "nome" (Bourdieu, 1990) a partir de seu corpo, sua aparência, sua beleza ou, como diria esse mesmo autor, seu capital físico.

Neste caso, é fácil perceber que a associação "corpo e prestígio" se tornou um elemento fundamental da cultura brasileira. Não é de estranhar que se tornou também um problema de investigação científica para melhor compreender a especificidade de nossa sociedade. 


\section{UM CORPO BRASILEIRO}

Será que ela vai continuar uma tradição?

Será que ela vai modificar uma geração?

Lá vem ela!

Miss Brasil 2000!

Rita Lee (Miss Brasil 2000)

Pesquisando, desde 1988, os novos e velhos arranjos conjugais em nossa sociedade, fui surpreendida por uma categoria extremamente presente no discurso de meus pesquisados: $O$ corpo.

Já na década de 1980, o antropólogo Gilberto Freyre, como sempre de forma pioneira e polêmica, buscou pensar o corpo da mulher brasileira. Em seu livro Modos de homem, modas de mulher, Freyre (1987) afirmava que:

Pode-se dizer da mulher que tende a ser, quanto a modas para seus vestidos, seus sapatos, seus penteados, um tanto maria-vai-com-as-outras. Portanto, a corresponder ao que a moda tem de uniformizante. Mas é da argúcia feminina a iniciativa de reagir contra essa uniformização absoluta de acordo com características pessoais que não se ajustem a imposições de uma moda disto ou daquilo. Neste particular, é preciso reconhecer-se, na brasileira morena, o direito de repudiar modas norte-européias destinadas a mulheres louras e alvas (Freyre, 1987: 33).

Freyre (1987) apontava como modelo de beleza da brasileira a atriz Sônia Braga: baixa, pele morena, cabelos negros, longos e crespos, cintura fina, bunda ("ancas") grande, peitos pequenos. Dizia, com certo tom de crítica, que este modelo de brasileira estava sofrendo um impacto norte-europeizante ou albinizante, ou ainda ianque, com o sucesso de belas mulheres como Vera Fischer: alta, alva, loira, cabelos lisos, com um corpo menos arredondado.

Este novo modelo de beleza para as brasileiras, já detectado por Freyre, ganhou muito mais força nas últimas décadas. Como disse a Veja, "As brasileiras não ficam velhas, ficam loiras" (www.veja.com.br em 07/06/2000), mostrando que a brasileira é uma das maiores consumidoras de tintura de cabelo em todo o mundo. Além de Vera Fischer, que permanece um ideal de beleza, Xuxa e, posteriormente, Gisele Bündchen tornaram-se modelos a serem imitados pelas brasileiras, ícones norte-europeizantes, diria Freyre. 
Freyre (1987) enaltecia o corpo da mulher brasileira, miscigenado, um corpo equilibrado de contrastes, e propunha uma consciência brasileira, dizendo que a mulher brasileira deveria seguir modas adaptadas ao clima tropical, em vez de seguir passivamente e, por vezes, grotescamente modas de todo européias ou norte-americanas: na roupa, no sapato, no adorno, no penteado, no perfume, no andar, no sorrir, no beijar, no comportamento, no modo de ser mulher. Eu ainda acrescentaria: no corpo. Freyre sugeria que as modas e os modismos não diziam respeito apenas às roupas ou penteados, mas também poderiam se tornar modas de pensar, de sentir, de crer, de imaginar e, assim, subjetivas, influírem sobre as demais modas. Ele aponta os excessos cometidos pelas mulheres mais inclinadas a seguir as modas, especialmente as menos jovens, para as quais modas sempre novas surgiriam como suas aliadas contra o envelhecimento.

Gilberto Freyre, duas décadas atrás, admitia que várias novidades no setor de modas de mulher tendem a corresponder a esse desejo da parte das senhoras menos jovens: o de rejuvenescerem. E a verdade, dizia ele, é que há modas novas que concorrem para o rejuvenescimento de tais aparências, favorecido notavelmente por cosméticos, tinturas e cirurgias plásticas.

$\mathrm{O}$ autor mostra, portanto, que as modas surgem visando uma preocupação central da mulher brasileira: permanecerem jovens. Nestas últimas décadas, esta preocupação cresceu enormemente, com novos modelos de mulher a serem imitados: cada vez mais jovens, belas e magras. Como afirmou Marcel Mauss (1974), é através da imitação prestigiosa que os indivíduos de cada cultura constroem seus corpos e comportamentos. Para Mauss, o conjunto de hábitos, costumes, crenças e tradições que caracterizam uma cultura também se refere ao corpo. Assim, há uma construção cultural do corpo, com uma valorização de certos atributos e comportamentos em detrimento de outros, fazendo com que haja um corpo típico para cada sociedade. Esse corpo, que pode variar de acordo com o contexto histórico e cultural, é adquirido pelos membros da sociedade por meio da imitação prestigiosa: os indivíduos imitam atos, comportamentos e corpos que obtiveram êxito e que viram ser bem-sucedidos.

Um exemplo atual do que dizia Freyre foi a polêmica causada no concurso de Miss Brasil de 2005. Com o título "Procura-se a mulher brasileira no Miss Brasil”, o jornalista Jamari França afirmou que

parecia um concurso de miss de país europeu. As misses foram apresentadas de biquíni por região do país... Apresentadas uma a uma, as misses eram todas de 
uma pele alva de quem nunca se deixou queimar nas praias de água doce do Rio Amazonas.

Até a Miss Bahia tem a pele branca de ascendência européia... Quando chegou mais embaixo, nas regiōes Sudeste e Sul, já não causava estranheza a presença de louras e morenas de olhos azuis ou verdes, já que é um biotipo mais comum nestas paragens.

Não se trata de ficar com um preconceito racial às avessas contra as brancas, mas a realidade incontestável é que o concurso não reflete a diversidade de tipos da mulher brasileira. Muitas vezes, quando uma miss entrava na passarela, a gente tinha impressão de que ela já tinha desfilado, tal a semelhança de tipos físicos. As nossas misturas, que resultam em mulatas de olhos verdes, beldades com traços indígenas e negras que assumem a raça com orgulho, botam muitas daquelas misses no chinelo. A impressão que se tem é que o concurso é aberto apenas à elite de cada estado, clubinhos fechados, sem que se procure nas ruas mulheres que representem a nossa diversidade. A mulher brasileira é das mais belas do mundo, com uma riqueza que ouso dizer ufanisticamente que nenhum outro país tem. Pena que nem todas elas subam à passarela do concurso. Falta Brasil no Miss Brasil (Jamari França, Globo Online, 15/04/2005).

Outro estudo muito interessante para discutir a especificidade do corpo brasileiro é o de Malisse (2002). Ao comparar o corpo da mulher brasileira com o da francesa, Malisse constatou que

enquanto, na França, a produção da aparência pessoal continua centrada essencialmente na própria roupa, no Brasil é o corpo que parece estar no centro das estratégias do vestir. As francesas procuram se produzir com roupas cujas cores, estampas e formas reestruturam artificialmente seus corpos, disfarçando algumas formas (particularmente as nádegas e a barriga) graças ao seu formato; as brasileiras expõem o corpo e freqüentemente reduzem a roupa a um simples instrumento de sua valorização; em suma, uma espécie de ornamento (Malisse, 2002: 110).

Dentro dessa lógica, o autor diz que a tendência das adolescentes francesas a se vestir como suas mães mostra que a roupa, na França, participa de um processo de envelhecimento da aparência, enquanto no Brasil, pelo contrário, a tendência é vestir-se como jovem até bem tarde. Analisando, particularmente, a cidade do Rio de Janeiro, o autor mostra que a distinção entre roupa de praia, roupa de cidade e roupa esportiva tende a desaparecer: 
as roupas brincam com as partes escondidas/expostas sem que o corpo se cubra muito mais ao passar da praia para a rua. Aqui, as formas femininas não são escondidas pelo efeito de camuflagem dos tailleurs, dos sobretudos ou dos cortes amplos, mas, pelo contrário, são realçadas: as mulheres vestem saias e calças de cintura baixa, valorizando assim quadris e nádegas, colocando-os em relevo, em cena... No Rio, as roupas são usadas sobretudo para valorizar as formas do corpo feminino, para exibi-las: a cintura e o busto são marcados, realçados... Esses corpos femininos trabalhados, moldados nas academias, só suportam roupas que deixem o corpo valorizado à mostra sob o tecido (Idem: 112-113).

No Brasil, e mais particularmente no Rio de Janeiro, o corpo trabalhado, cuidado, sem marcas indesejáveis (rugas, estrias, celulites, manchas) e sem excessos (gordura, flacidez) é o único que, mesmo sem roupas, está decentemente vestido (Goldenberg, 2002). Pode-se pensar, neste sentido, que, além de o corpo ser muito mais importante do que a roupa, ele é a verdadeira roupa: é o corpo que deve ser exibido, moldado, manipulado, trabalhado, costurado, enfeitado, escolhido, construído, produzido, imitado. É o corpo que entra e sai da moda. A roupa, neste caso, é apenas um acessório para a valorização e exposição deste corpo da moda.

\section{O CORPO COMO VALOR}

Todos vimos, na televisão, modelos torturados por seguidas cirurgias plásticas. Transformaram seus seios em alegorias para entrar na moda da peitaria robusta das norte-americanas. Entupiram as nádegas de silicone para se tornarem rebolativas e sensuais, garantindo bom sucesso nas passarelas do samba. Substituíram os narizes, desviaram costas, mudaram o traçado do dorso para se adaptarem à moda do momento e ficarem irresistíveis diante dos homens. E, com isso, Barbies de funkaria, provocaram em muitas outras mulheres - as baixinhas, as gordas, as de óculos - um sentimento de perda de auto-estima

Rita Lee, março, 2004

Se o corpo é a imagem da sociedade, que sociedade é essa que está representada nos corpos dos brasileiros? Na última década, tenho me preocupado em pensar sobre que modelo de corpo tem prestígio em nossa cultura e, conseqüentemente, qual é o corpo que é imitado (ou desejado) pelas mulheres e, também, pelos homens. O início desta minha preocupação pode ser verificado no livro $N u$ \& vestido (Goldenberg, 2002), onde reuni resultados de ampla pesquisa realizada 
com 1279 moradores da cidade do Rio de Janeiro, analisando seus valores e comportamentos. Nessa pesquisa, verifiquei que o corpo é um valor para os segmentos das camadas médias cariocas. No mesmo livro, reuni pesquisas de antropólogos brasileiros e estrangeiros que tomaram o corpo como questão central na construção da identidade do brasileiro, mostrando as singularidades e complexidades da construção social deste corpo em nossa cultura. Dois anos depois, publiquei $D e$ perto ninguém é normal: corpo, sexualidade, gênero e desvio na cultura brasileira (Goldenberg, 2004), onde dedico vários capítulos à discussão sobre o papel do corpo nos atuais relacionamentos afetivo-sexuais, nos comportamentos dos jovens, na infidelidade, entre outros. A repercussão dos dois livros, para muito além do mundo acadêmico, revela como a preocupação com determinado modelo de corpo se tornou um marco importante (talvez o mais importante) desta geração e época.

$\mathrm{Na}$ pesquisa realizada com homens e mulheres das camadas médias cariocas, ao perguntar "O que você mais inveja em uma mulher?", as respostas femininas foram a beleza, o corpo e a inteligência. Já para a questão "O que você mais inveja em um homem?”, eles responderam: a inteligência, o poder econômico, a beleza e o corpo. Parece, para os pesquisados, que é muito melhor ser homem do que ser mulher, pois, para a questão "O que você mais inveja em um homem?", grande parte das mulheres respondeu: "liberdade" e inúmeras outras características masculinas associadas a um comportamento mais livre do que o feminino, entre as quais se destaca a inveja por o homem "fazer xixi em pé". Já cerca de $40 \%$ dos homens pesquisados disseram não invejar "nada" nas mulheres. Os poucos que disseram invejar algo apontaram maternidade, capacidade de engravidar e sensibilidade. Respostas que reafirmam as representaçóes associadas a uma suposta "natureza" masculina e feminina em nossa cultura.

Também com relação à atração entre os sexos, o corpo tem um papel fundamental. Ao perguntar "O que mais te atrai em um homem?", as pesquisadas disseram: a inteligência, o corpo e o olhar. Para a questão "O que mais te atrai em uma mulher?”, os pesquisados responderam: a beleza, a inteligência e o corpo. Quando a atração é sexual, o corpo ganha um destaque ainda maior. Na pergunta "O que mais te atrai sexualmente em um homem?", as mulheres disseram: o tórax, o corpo e as pernas. Já os homens, para a questão "O que mais te atrai sexualmente em uma mulher?", responderam: a bunda, o corpo e os seios.

Só quando proponho aos pesquisados que escrevam um anúncio com o objetivo de encontrar um parceiro é que este corpo aparece seguido de alguns adjetivos, como "definido", "malhado", "trabalhado", "sarado", "saudável", "atlético", "bonito", "forte” (Goldenberg, 2002). 
Enquanto, nos anúncios, as mulheres destacam que são magras, loiras, de cabelos longos e lisos, lindas e carinhosas, os homens enfatizam que são altos, fortes, bem-dotados e inteligentes.

No que diz respeito à maneira como homens e mulheres pensam o corpo feminino, percebe-se um grande distanciamento. Matéria da revista Época trouxe como título "O corpo que eles desejam... não é o que elas querem ter" (Goldenberg, 2004). A reportagem mostra um fenômeno esquizofrênico da nossa época: mulheres querem seduzir homens com um corpo que está longe da preferência masculina. A matéria revela que o padrão de beleza desejado pelas mulheres tem sido construído por meio de imagens das supermodelos, que se consagraram a partir dos anos 1980 e conquistaram status de celebridade nos 1990. Doenças como anorexia e bulimia se tornaram quase uma epidemia nos últimos anos, em uma geração que cresceu tentando imitar o corpo de Cindy Crawford, Linda Evangelista, Claudia Schiffer e, mais recentemente, da brasileira Gisele Bündchen. É curioso observar que os homens que responderam ao meu questionário elegeram como suas musas Sheila Carvalho, Luma de Oliveira, Luana Piovani, Mônica Carvalho e outras "gostosas" que estão muito longe das medidas das modelos das passarelas, modelos que possuem os corpos invejados (e, muitas vezes, imitados) pelas pesquisadas.

Dados recentes demonstram que a brasileira é campeã na busca de um corpo perfeito (Edmonds, 2002). Segundo a Sociedade Brasileira de Cirurgia Plástica, o brasileiro, especialmente a mulher brasileira, se tornou, logo após o norte-americano, o povo que mais faz plástica no mundo: 621.342 brasileiros se submeteram a pelo menos um procedimento cirúrgico em 2003. Estima-se que em 2004 tenham sido 800.000 pessoas. As mulheres são a esmagadora maioria: $70 \%$. De 2002 a 2003 , cresceu em $43 \%$ o número de jovens que se operam: $13 \%$ do total dos que fazem plástica são jovens de menos de 18 anos, fato que chamou a atenção da Sociedade Internacional de Cirurgia Plástica. A lipoaspiração é a cirurgia mais realizada (56\%), seguida da operação das mamas (38\%), face (30\%), abdome $(23 \%)$, pálpebras $(18 \%)$ e nariz $(12 \%)$. No quesito insatisfação com o próprio corpo, as brasileiras só ficam atrás das japonesas (37\% das brasileiras se disseram insatisfeitas) em uma pesquisa realizada com 3.200 mulheres de dez países. Só 1\% das mulheres brasileiras se acham bonitas. O Brasil é o país em que mais se valoriza as modelos. $54 \%$ das brasileiras já consideraram a possibilidade de fazer plástica e $7 \%$ já fizeram, índice mais alto entre os países pesquisados. Mas o que torna o Brasil especial nessa área é o ímpeto com que as pessoas decidem operar-se e a rapidez com que a decisão é tomada. São três as principais motivações para fazer uma plástica: atenuar os efeitos do envelhecimento; corrigir defeitos físicos e es- 
culpir um corpo perfeito. No Brasil, esta última motivação é a que mais cresce: a busca de um corpo perfeito.

Também com relação ao uso de botox e ao implante de próteses de silicone, o Brasil é o segundo no mundo, logo após os Estados Unidos. São 85 mil cirurgias de mama e 30 mil implantes de silicone por ano. Desde 1995, o número de cirurgias para aumentar os seios das brasileiras quintuplicou. Nos últimos dez anos, cresceu 300\% o número de cirurgias nos seios das adolescentes.

Bourdieu (1999) discute a "dominação masculina" que obriga homens a serem fortes, potentes e viris (daí a ênfase com que os pesquisados falam sobre altura, força física, tamanho do tórax e demonstram a preocupação com o tamanho do pênis), enquanto as mulheres devem ser delicadas, submissas, apagadas (o que corresponde ao modelo de mulher magra que predomina atualmente). Milhares de jovens sofrem de anorexia e bulimia. Só em Porto Alegre, coincidentemente uma das capitais de onde despontam as modelos brasileiras mais bemsucedidas internacionalmente, $13 \%$ de adolescentes do sexo feminino sofrem de anorexia ou de bulimia. O psiquiatra José Carlos Appolinário, especialista em transtornos alimentares do Instituto de Psiquiatria da UFRJ e do Instituto Estadual de Diabetes e Nutrição, afirmou que a publicidade de moda deveria advertir, a exemplo dos anúncios de fumo, que a magreza exagerada leva à anorexia, uma doença grave que mata 5,9\% de suas vítimas.

Uma das causas da anorexia e da bulimia, segundo especialistas, é a mania de emagrecer. Por problemas psicológicos, mas também pressionadas pela sociedade, as adolescentes passam dos freqüentes regimes alimentares a uma rejeição incontrolável pela comida e a fazer exercícios físicos de forma exagerada, tentando compensar a baixa auto-estima. Mas a anorexia parece ter deixado a condição de patologia para a categoria de estilo de vida. Inúmeras páginas pessoais na internet divulgam movimentos "pró-anorexia" e "pró-bulimia". São as "amigas da Ana" e "amigas da Mia", dando dicas para aquelas que desejam aderir a um estilo de vida que tem a magreza como modelo a ser seguido.

Uma reportagem da revista Isto É (Online em 25/10/2002) revelou que um exército de adolescentes está usando a internet para ensinar outras jovens a serem anoréxicas, pregando a inapetência e a autopunição sempre que comerem. As páginas são assustadoras, com fotografias de meninas esquálidas apontadas como modelos de beleza, dicas para enganar os pais e amigos para fingir que estão alimentadas e formas de se punir, caso comam algo que engorda. Os sites divulgam os seguintes "mandamentos": "você não deve comer sem se sentir culpada. Você não deve comer algo que engorda sem se punir depois. Ser magra é mais importante do que ser saudável. Você nunca está magra. Ser magra é a coisa mais impor- 
tante que existe". Outras dicas são: "Não engula! Morda, mastigue e jogue fora! Durma pouco. Dessa forma você queima mais calorias. Limpe banheiros ou ambientes bem sujos. Você perde a fome. Diga que você vai comer no quarto e jogue a comida fora. Em casa, diga que vai comer com os amigos. Aos amigos você diz que já comeu em casa”.

Por outro lado, em 2004, dois jovens brasileiros morreram por usar anabolizantes bovinos. Um deles injetou um anabolizante usado ilegalmente na engorda rápida de gado. Policiais prenderam quatro jovens em Goiânia com 74 frascos de anabolizantes - alguns deles para uso animal. $\mathrm{O}$ material, fabricado na Argentina, seria vendido em academias de ginástica para praticantes de musculação. Um trabalho interessante sobre a obsessão masculina em responder a um ideal de ser homem, ancorado em um corpo musculoso, na performance sexual e no tamanho do pênis, é $O$ complexo de Adonis (Pope, Phillips \& Olivardia, 2000). Seus autores afirmam que milhões de homens nos Estados Unidos estão sacrificando aspectos importantes de suas vidas para se exercitarem compulsivamente nas academias. Milhões de dólares são gastos em suplementos alimentares e esteróides anabolizantes, que causam câncer, hepatite e outras doenças graves. Além destas drogas perigosas, os distúrbios alimentares são cada vez mais freqüentes neste universo. Os autores revelam que mais de um milhão de norte-americanos, especialmente adolescentes e meninos, desenvolveram o distúrbio dismórfico corporal, representado por uma preocupação excessiva com supostas falhas na aparência, como o tórax pequeno ou o pênis pequeno. Basta, segundo os autores, uma rápida olhada na internet para descobrir o exagero de técnicas de aumento de pênis hoje comercializadas, sendo a indústria do aumento do pênis uma parte significativa da crescente indústria da imagem corporal masculina, estimulando e aumentando as inseguranças dos homens a respeito dos seus corpos. O estudo destaca que estes homens, meninos e adolescentes, sofrem silenciosamente, em segredo, não conversam sobre seus problemas, uma vez que, em nossa sociedade, os "homens de verdade" não devem demonstrar preocupação com a aparência, pois podem ser considerados afeminados ou gays.

Pierre Bourdieu (1999), em A dominação masculina, afirmou que os homens tendem a se mostrar insatisfeitos com as partes de seu corpo que consideram "pequenas demais" enquanto as mulheres dirigem suas críticas às regióes de seu corpo que lhes parecem grandes demais. $\mathrm{O}$ autor acredita que a dominação masculina, que constitui as mulheres como objetos simbólicos, tem por efeito colocálas em permanente estado de insegurança corporal, ou melhor, de dependência simbólica: elas existem, primeiro, pelo e para o olhar dos outros, como objetos receptivos, atraentes, disponíveis. Delas se espera que sejam "femininas", ou seja, 
sorridentes, simpáticas, atenciosas, submissas, discretas, contidas, ou até mesmo apagadas. Neste caso, ser magra contribui para esta concepção de ser mulher. Sob o olhar dos outros, as mulheres se vêem obrigadas a experimentar constantemente a distância entre o corpo real, a que estão presas, e o corpo ideal, o qual procuram infatigavelmente alcançar.

No entanto, para Bourdieu (1999), a estrutura impõe suas pressões aos dois termos da relação de dominação, portanto, aos próprios dominantes, que são dominados por sua dominação, fazendo o esforço desesperado, e bastante patético, mesmo em sua triunfal inconsciência, que todo homem tem que fazer para estar à altura de sua idéia infantil de homem. A preocupação com altura, força física, potência, poder, virilidade e, particularmente, com o tamanho do pênis pode ser vista como exemplo desta dominação que o dominante também sofre.

\title{
Muito LONGE DE SER “MEIO LeILA Diniz”
}

\author{
Toda mulher quer ser amada \\ Toda mulher quer ser feliz \\ Toda mulher se faz de coitada \\ Toda mulher é meio Leila Diniz
}

Rita Lee (Todas as mulheres do mundo)

No Rio de Janeiro, cidade considerada a mais bela do mundo, onde as praias e a temperatura elevada durante quase todo o ano favorecem o desnudamento, a centralidade que a aparência física assume na vida cotidiana é muito mais evidente. Estudei o papel do corpo na cultura carioca em dois diferentes momentos e contextos históricos. O primeiro estudo foi a análise da trajetória de Leila Diniz, em minha tese de doutorado.

No dia 25 de março de 2005, Leila Diniz estaria completando 60 anos. Décadas após a sua morte, não consigo lembrar de outro nome tão marcante na história das mulheres brasileiras. Ao ver uma jovem grávida de biquíni, na praia de Ipanema, sua imagem surge imediatamente na lembrança. Mas não só nestes momentos. Quando vejo mulheres extremamente preocupadas com o peso, rugas, celulite ou estrias, penso no corpo livre de Leila Diniz. Em uma matéria recente, que lembrava os 60 anos de Leila, a jornalista insistiu na pergunta: "Se Leila estivesse viva hoje, ela teria feito plástica?”. Respondi que, com certeza, não. Que ela continuaria uma mulher livre, que busca o prazer e a alegria. Uma mulher que não teria medo de envelhecer, nem mutilaria seu corpo, mas que continuaria exercendo sua sexualidade, sem medo dos preconceitos e das acusações. Foi inte- 
ressante que, pela primeira vez, uma jornalista fez este tipo de questão, o que sugere que esta preocupação com o corpo teria se generalizado entre as mulheres brasileiras. Sugere, também, que Leila Diniz, como a mulher libertária que foi, teria resistido à ditadura da beleza.

Outra questão, esta sim sempre presente nas entrevistas, foi "Quem seria a Leila Diniz de hoje? Que mulher é tão revolucionária quanto Leila foi nos anos 60?”.

Tenho dificuldade para enxergar uma nova Leila Diniz. Ao contrário, encontro mulheres aprisionadas por um modelo de perfeição e que deixam de viver plenamente suas vidas, inclusive sua sexualidade, pela extrema preocupação com o corpo. Como mostrei em estudo anterior (2004), a obsessão com determinado modelo de corpo tem atrapalhado a vida sexual de muitas mulheres. Em uma recente pesquisa nacional sobre a vida sexual dos brasileiros, com 3.000 homens e mulheres, de todas as classes sociais, coordenada pela psiquiatra Carmita Abdo (2004), do Projeto Sexualidade do Hospital das Clínicas de São Paulo, um dos maiores problemas encontrados foi a falta de desejo: $35 \%$ das mulheres pesquisadas não sentem nenhuma vontade de ter relaçôes. Um dos principais motivos dessa falta de desejo é uma questão cultural que inibe a libido: a angústia de não corresponder à imagem da mulher com o corpo perfeito que aparece nas revistas e nas propagandas de TV. Abdo ressalta que numa sociedade altamente erotizada no plano da moda e da mídia, que privilegia cada vez mais o corpão, a cama pode ser o palco de uma tremenda frustração para quem não apresenta medidas próximas das perfeitas. Diante da impossibilidade de exibir esse padrão, o desejo é pouco a pouco reprimido, até sumir de vez - ou transubstanciar-se em neuroses. Lipovetsky (2000) analisa a "febre da beleza-magreza-juventude", que exerce uma "tirania implacável sobre a condição das mulheres”. Para o autor,

a obsessão da magreza, a multiplicação dos regimes e das atividades de modelagem do corpo, os pedidos de redução de culotes e de modelagem até dos narizinhos arrebitados testemunham o poder normalizador dos modelos, um desejo maior de conformidade estética que se choca frontalmente com o ideal individualista e sua exigência de personalização dos sujeitos (Lipovetsky, 2000: 143).

Lipovetsky acrescenta, ainda, que, de forma contraditória, quanto mais se impõe o ideal de autonomia individual, mais se aumenta a exigência de conformidade aos modelos sociais de corpo. Paradoxalmente, o desenvolvimento do individualismo feminino e a intensificação das pressões sociais das normas do corpo caminham juntas. De um lado, o corpo feminino se emancipou amplamente de suas antigas servidões - sexuais, procriadoras ou indumentárias; de outro, encon- 
tra-se, atualmente, submetido a coerções estéticas mais regulares, mais imperativas e mais geradoras de ansiedade do que antigamente.

É interessante pensar as razões desta obsessão com o corpo em mulheres que poderiam usufruir todas as conquistas da geração anterior, dos anos 1960 e 1970 , quando houve uma verdadeira revolução do comportamento feminino, principalmente no que se refere à sexualidade e à liberdade (Goldenberg, 1995). Por que as mulheres brasileiras e, mais particularmente, as jovens cariocas, estão tão longe de ser "meio Leila Diniz"?

Quando, em 1971, Leila Diniz exibiu sua barriga grávida de biquíni, na praia de Ipanema, escandalizou e lançou moda. Foi capa de revistas e manchete de jornais por ter sido a primeira mulher a não esconder sua barriga em roupas soltas e escuras, consideradas mais adequadas a uma grávida. Não só engravidou sem ser casada como exibiu uma imagem concorrente à grávida tradicional, que escondia sua barriga. A barriga grávida materializou, objetivou, corporificou seus comportamentos sexuais transgressores. Ícone das décadas de 1960 e 1970, Leila Diniz permanece, até hoje, como símbolo da mulher carioca, que encarna, melhor do que ninguém, o espírito da cidade: corpo seminu, sedução, prazer, liberdade, sexualidade, alegria, espontaneidade.

Ao analisar a trajetória de Leila Diniz, encontrei uma mulher considerada "revolucionária". Não uma feminista ou alguém que defendia bandeiras políticas, mas uma jovem que, com seu próprio corpo, mudou profundamente valores e comportamentos da mulher brasileira. Mostrei, em minha tese (Goldenberg, 1995), depoimentos que destacavam que muitas mulheres "faziam" ou "diziam" as mesmas coisas que Leila, mas Leila "dizia e fazia", acumulando assim reconhecimento dos que desejavam contestar o modelo tradicional de ser mulher. Portanto, o reconhecimento que Leila conquistou, até hoje, está ligado à correspondência entre seus comportamentos efetivos e seu discurso.

Leila Diniz encarna a imagem de uma jovem livre e feliz: sua maneira de exibir o corpo, seu uso da linguagem, sua conduta sexual, suas escolhas de amigos e parceiros amorosos estão inteiramente presentes em sua ética e estética de vida. Percebe-se nitidamente, em Leila, uma postura de transgressão simbólica, estilo que encerra a afirmação de uma contra-legitimidade, por exemplo, pela intenção de dessacralização dos valores da moral e da estética dominantes, através de um comportamento sexual livre, de uma linguagem irreverente e sem censuras, da imposição de novos padrões estéticos e ruptura de tabus sociais (como a exibição da barriga grávida de biquíni), antítese quase perfeita do moralismo de determinados grupos que exigiam, nos anos 1960, um comportamento feminino sério e regrado. 
Com as idéias de poder simbólico, luta simbólica e revolução simbólica (Bourdieu, 1990), pode-se compreender melhor a definição de Leila Diniz como uma mulher "revolucionária", recorrentemente presente no material coletado para minha tese. Ao entender a luta simbólica como uma luta que pode ser realizada por um indivíduo que, na sua existência cotidiana, busca mudar as categorias de percepção e de apreciação do mundo social, transformando a realidade social, pode-se perceber a significação social de Leila Diniz ao introduzir padrões de corpo e de comportamento sexual contestadores da ética e da estética dominantes. A entrevista a $O$ Pasquim (Goldenberg, 1995), e a sua ampla repercussão nacional, revela a sua "revolução simbólica". Suas opiniōes sobre liberdade sexual feminina e sua linguagem livre e irreverente, repleta de palavrōes, surpreenderam os leitores, o que provavelmente explica a violência das reações após a publicação: ela é considerada puta, subversiva, sofre perseguiçōes da ditadura militar, quase é presa, passa a ter dificuldades para conseguir trabalhos, especialmente na televisão.

Os militares, que denunciaram e perseguiram Leila como uma subversiva, não estavam inteiramente errados. $\mathrm{O}$ poder de nomear, sobretudo o de nomear o inominável, o que ainda não foi percebido ou que está recalcado, é um poder considerável, é um poder de criação, como afirma Bourdieu (1990), já que o poder das palavras pode ser percebido quando elas fazem com que sejam vistas ou previstas coisas que só existiam no estado implícito ou confuso.

Leila Diniz viveu em um momento de profundas transformações sociais. Seu sucesso e sua projeção nacional ocorreram a partir de 1967, sempre crescentes até 1970. É impossível falar de sua "revolução" sem visualizar o clima político vivido no país: repressão, censura, torturas etc. A juventude encontrava-se dividida entre o engajamento político e o "desbunde" das drogas. Apesar de conviver com jovens hippies e militantes políticos, Leila "escolheu" um outro caminho, um caminho de autoconhecimento, reforçado aos 16 anos com a busca de terapia psicanalítica, ainda incipiente no Brasil dos anos 1960. Antecipa-se, assim, a um processo que ocorrerá com maior intensidade na década seguinte. Leila parece ter tido a sensibilidade necessária para pressentir estes movimentos de mudanças (psicanálise, liberação sexual da mulher, "soltura" do corpo e da linguagem, entre outros) e a audácia indispensável para responder ao desafio social, abandonando os caminhos mais prováveis para uma jovem de sua geração. Assim, ela se distingue das jovens das camadas médias de sua geração, ao mesmo tempo que concretiza os desejos e aspiraçōes destas jovens.

Leila Diniz criou um estilo próprio, marcou uma diferença, como uma jovem mulher nos anos 1960. Em sua estratégia de distinção (cabe lembrar que esta estratégia não é consciente, mas produto de um habitus e das exigências do 
próprio campo), combinou características percebidas como opostas, como: a iniciativa sexual e a meiguice; os palavrôes e a sensualidade; a vida intensa e agitada, cercada de amigos e namorados, com a busca de autoconhecimento (por meio dos diários, da psicanálise e da profissão de atriz). Leila foi criticada por feministas, que a consideravam "alienada", mas viveu na prática a liberação feminina. Foi perseguida pela ditadura militar e protegida por Flávio Cavalcanti, considerado um homem de direita. Leila Diniz assumiu, de forma feminina, comportamentos aceitos apenas para os homens. Esta capacidade de combinar opostos, recorrentemente lembrada nos depoimentos, fez dela uma mulher extremamente singular, pois combinou, de maneira harmônica, características percebidas como completamente opostas em nossa cultura.

Leila Diniz tornou-se um modelo de transgressão a partir, principalmente, de sua "soltura" do corpo e da linguagem e passou a ser instauradora de novos padrôes femininos e de novos modos de expressão e de ação. Tornou-se um modelo de mulher a ser imitado. Eleita rainha da Banda de Ipanema, musa de O Pasquim, sua imagem social foi cada vez mais a de uma mulher livre e feliz, representante ideal da alegria e irreverência do povo carioca. Os reforços positivos que recebeu, através, principalmente, do espaço de destaque que lhe foi reservado na imprensa alternativa e na grande imprensa, fez com que Leila afirmasse cada vez mais radicalmente a sua postura de transgressão às censuras éticas, especialmente em matéria sexual. Daí a barriga grávida exibida de biquíni, de forma pioneira, levando uma filha gerada fora do casamento.

Leila Diniz foi, então, uma mulher à frente do seu tempo e produto do seu tempo. Bourdieu (1990) lembra que o estilo pessoal não é senão um desvio, regulado e codificado, em relação a um estilo próprio de uma época ou de uma classe. Basta, então, cada um deixar-se levar por sua natureza, isto é, pelo que a história fez deles, para estarem naturalmente ajustados ao mundo histórico com o qual se defrontam, para fazerem o que é preciso, para realizarem o futuro potencialmente inscrito nesse mundo em que eles estão como peixes dentro d'água.

O corpo de Leila Diniz (e de muitas mulheres de sua geração) era um corpo voltado para o prazer, para o livre exercício da sexualidade, que exibia sua beleza e plenitude à luz do sol. $\mathrm{O}$ corpo de muitas mulheres de hoje, como constatei na pesquisa realizada com indivíduos das camadas médias urbanas cariocas, é um corpo controlado, mutilado, que prefere a escuridão para esconder suas imperfeições. Em pouco mais de três décadas, assistimos a uma enorme transformação do corpo carioca: do exercício do prazer à busca da perfeição estética, da liberdade à submissão aos modelos, do erotismo à falta de desejo. Concluo, então, com a 
constatação de que, no Brasil do século XXI, estamos muito longe de poder afirmar que "toda mulher é meio Leila Diniz".

\section{REFERÊNCIAS BIBLIOGRÁFICAS}

Abdo, C. (2004). Descobrimento sexual do Brasil. São Paulo: Summus.

Bourdieu, P. (1990). Coisas ditas. São Paulo: Brasiliense.

. (1999). A dominação masculina. Rio de Janeiro: Bertrand Brasil.

Edmonds, A. ( 2002). No universo da beleza: notas de campo sobre cirurgia plástica no

Rio de Janeiro. Em Nu \& vestido (pp. 189-261). Rio de Janeiro: Record.

Freyre, G. (1987). Modos de homem, modas de mulher. Rio de Janeiro: Record. - (2000). Entrevista dada a Veja, www.veja.com.br em 07/06/2000.

Goldenberg, M. (1995). Toda mulher é meio Leila Diniz. Rio de Janeiro: Record.

- (2002). Nu \& vestido. Rio de Janeiro: Record.

- (2004). De perto ninguém é normal. Rio de Janeiro: Record.

- (1995). Toda mulher é meio Leila Diniz. Rio de Janeiro: Record. Entrevista realizada em 20 de Novembro de 1969 para O Pasquim, no 22, Rio de Janeiro.

Isto $E$ Online, www.terra.com.br/istoe/1725/medicina/1725_praga_virtual.htm, em 25/ $10 / 2002$.

Lipovetsky, G. (2000). A terceira mulher. São Paulo: Companhia das Letras.

Malisse, S. (2002). Em busca dos (H)alteres-ego: olhares franceses nos bastidores da corpolatria carioca. Em Nu \& vestido (pp. 79-137). Rio de Janeiro: Record.

Mauss, M. (1974). As técnicas corporais. Sociologia e antropologia. São Paulo: EPU/EDUSP. Pope, H.; Phillips, K.; Olivardia, R. (2000). O complexo de Adonis. Rio de Janeiro: Campus.

Recebido em 1 de julho de 2005 Aceito para publicação em 18 de agosto de 2005 